\title{
Miniaturized Concentric Hexagonal Fractal Rings Based Monopole Antenna for WLAN/WiMAX Application
}

\author{
Kahina DJAFRI ${ }^{1}$, Mouloud CHALLAL ${ }^{1}$, Rabia AKSAS ${ }^{2}$, Faiza MOUHOUCHE ${ }^{1}$, Mokrane DEHMAS ${ }^{1}$ \\ ${ }^{1}$ Signals and Systems Laboratory, Institute of Electrical and Electronic Engineering, \\ University M'Hamed BOUGARA of Boumerdes, 35000 Boumerdes, Algeria \\ ${ }^{2}$ Ecole Nationale Polytechnique, Department of Electronics, 16000 Algiers, Algeria
}

k.djafri@univ-boumerdes.dz,m.challal@univ-boumerdes.dz

Submitted May 28, 2018 / Accepted November 13, 2018

\begin{abstract}
In this paper a new antenna design technique is introduced in order to achieve tri-band operation as well as antenna miniaturization. The technique consists of using two concentric first-iterative hexagonal rings connected to each other as a radiating patch fed with a Y-shaped microstrip line. The proposed antenna operates at three frequency bands to cover 2.4/5.8 GHz WLAN bands and 3.5/5.5 GHz WiMAX bands applications. The numerical analysis and simulation are carried out with CST MWS. The measured return losses of the proposed antenna show good performance and good agreement with the simulated ones. Consequently the proposed antenna with compact size of $9.7 \mathrm{~mm} \times 17 \mathrm{~mm} \times 1.63 \mathrm{~mm}$ is well suited for wireless applications.
\end{abstract}

\section{Keywords}

Fractal antenna, tri-band, miniaturization, WLAN, WiMAX

\section{Introduction}

With the rapid development in the communication systems, there is an increasing demand for compact size antennas. Besides, more requirements in terms of multiband and broad operation are needed. Consequently, several studies have been conducted to design miniaturized multiband antennas which can support multiple communication applications [1-3]. Thus, numerous antenna size reduction techniques have been reported elsewhere; for example, introduction of defected microstrip structure (DMS) [4], using a defected ground structure (DGS) [5-7] and loading the patch with shorting posts [8].

The introduction of fractal geometries in the antenna design is very interesting solution to achieve compact, low profile with multi-band and broadband characteristics. This is the result of the attractive properties of fractal geometries which are self-similarity and space filling [8-15]. Multiband and broadband [8-13] behavior is the result of the self-similarity property and the size reduction is achieved with space filling property [14-17].

In this paper, a new technique of miniaturization is proposed and investigated. The technique consists of using two concentric fractal shaped rings as radiating patch. The two rings are connected with a microstrip line to achieve triple band operation as well as size reduction. Based on this technique a compact tri-band mictrostrip patch antenna is designed and proposed. The radiating patch based on first-order hexagonal rings is fed with a Y-shaped transmission line as can be seen in Fig. 1. Thus, the antenna resonant frequencies can be tuned by changing the dimensions of the two fractal rings as well as the dimensions of the Y-shaped feed line. In order to validate the proposed technique, the antenna is simulated, fabricated and measured. The proposed tri-band antenna with compact size of $9.3 \times 17 \times 1.63 \mathrm{~mm}^{3}$ operates at three different bands coverings the $2.4 / 5.6 / 5.8 \mathrm{GHz}$ WLAN and $3.5 \mathrm{GHz}$ WiMAX applications. The simulated and measured return losses of the proposed antenna are presented and discussed.

\section{Antenna Structure}

Figure 1 shows the geometry of the proposed two concentric fractal rings dual-band antenna along with its dimensions, fabricated on a $1.63 \mathrm{~mm}$ thick FR4 substrate with permittivity and loss tangent of 4.3 and 0.02 , respectively. The proposed antenna with a planar size of only $9.3 \times 17 \mathrm{~mm}^{2}$ is composed of two connected concentric fractal shaped rings acting as a radiating element and a Y-shaped feed structure printed on the top side of the substrate and a partial ground plane embedded in the other side of the substrate.

The proposed fractal ring shape is selected for antenna miniaturization issue and its procedure of generation is illustrated in Fig. 1(c). The second fractal ring, which has the same center as the first one, connected to the outer ring is used to generate multiple resonances and to achieve compactness. Hence the resulted antenna resonates at three different frequencies covering the $2.4 / 5.6 / 5.8 \mathrm{GHz}$ WLAN 
and $3.5 \mathrm{GHz}$ WiMAX bands. Furthermore, the slot etched in the ground plane is used to improve the impedance matching of the antenna. After an extensive simulation study, the geometrical parameters of the antenna have been optimized and are listed in Tab. 1. The antenna design and study is done with help of a powerful full wave electromagnetic simulator CST suite 2017.

\section{Simulation Results and Parametric Studies}

In order to understand why the second fractal ring is used and how it affects the antenna resonances, different antennas involved in the design evolution are simulated and studied. The three antennas involved in the design evolution are illustrated in Fig. 2 and their simulated return losses are plotted in Fig. 3. Initially, a single band antenna is designed as illustrated in configuration Ant. 1 of Fig. 2. This antenna is composed of a first-order hexagonal fractal ring radiating patch fed by a $\mathrm{Y}$-shaped transmission line. The introduction of the fractal shaped radiating ring increases the total current path length as a result of which Ant. 1 resonant at $3.5 \mathrm{GHz}$ as illustrated in Fig. 3. If the parameter $\mathrm{S} 1$ is further increased to $2.7 \mathrm{~mm}$ (maximum length before overlapping), the resonant frequency decreases and reaches down to $3.26 \mathrm{GHz}$ (not able to reach the desired frequency of $2.45 \mathrm{GHz}$ ). Thus, the tuning of $S_{1}$ for Ant. 1 has a limitation and cannot shift the resonance as low as $2.45 \mathrm{GHz}$. This is why the second fractal ring is introduced in this work in order to create a resonance at $2.45 \mathrm{GHz}$ without increasing the antenna dimensions. The use of a parasitic element, when correctly coupled to the driven monopole, is a useful mechanism to create a broadband and a dual-band antenna [18], [19]. By loading Ant. 1 by the second fractal ring to design Ant. 2, the electromagnetic coupling (EM) between the two rings has led to dual band operation as well as the first resonance shift to $3.44 \mathrm{GHz}$ as can be seen in Fig. 3. To achieve compact size and triple band operation the two fractal rings are connected to each other by means of a strip line (Ant. 3) as can be seen in Fig. 2. It can be noted from the figure that the simulated $10-\mathrm{dB}$ impedance bandwidths of the three operating bands were $2.43 \%(2.43-2.49 \mathrm{GHz}), 23.1 \%$ $(3.25-4.10 \mathrm{GHz})$ and $25.3 \%(5.43-7.0 \mathrm{GHz})$.

The simulated return losses of the proposed antenna for different positions of the connecting strip are shown in Fig. 4. It is clearly seen from the figure that the connection position affects significantly the antenna operating bands. When the connection is set at position $\mathrm{P} 1$ as illustrated in Fig. 4(a), the antenna operates at two frequency bands centered at $2.43 \mathrm{GHz}$ and $3.92 \mathrm{GHz}$. When the connection is established at position P2 (Proposed antenna), three operating bands are obtained. However, if the connection is placed at P3 only two bands are exited whereas if the connection is placed at P4 only one mode is exited. Consequently, optimum results are obtained for connection strip placed at P2.

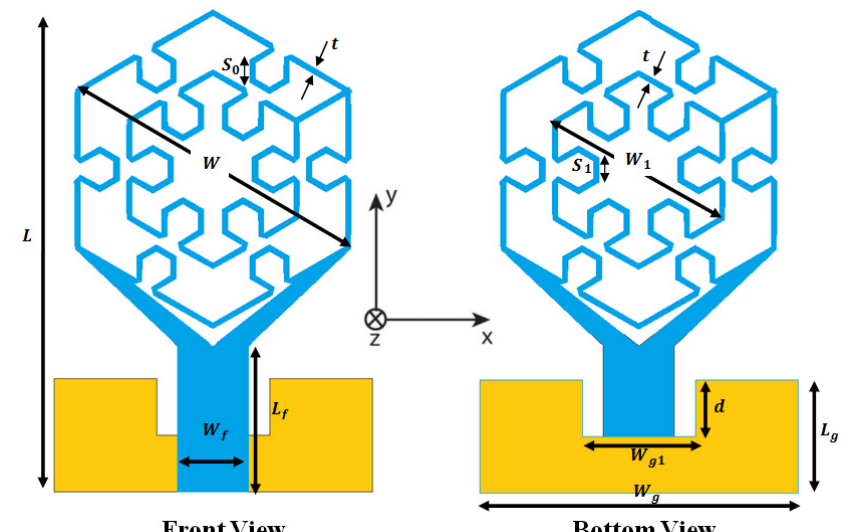

(a)

(b)
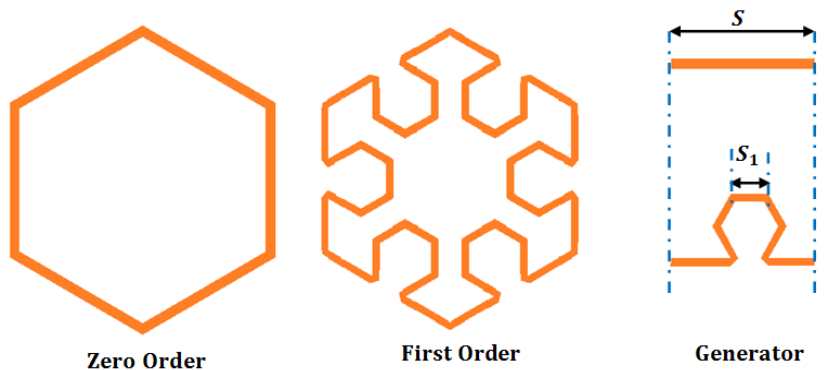

(c)

Fig. 1. Geometry of the proposed antenna:, (a) top view, (b) bottom view and, (c) the recursive-generation procedure for a hexagonal fractal curve.

\begin{tabular}{|c|c|c|c|}
\hline Parameter & Value (mm) & Parameter & Value (mm) \\
\hline$L$ & 17 & $W$ & 10.7 \\
\hline$L_{\mathrm{f}}$ & 5.42 & $L_{\mathrm{g}}$ & 4 \\
\hline$W_{\mathrm{f}}$ & 2.5 & $W_{\mathrm{g}}$ & 4.5 \\
\hline$t$ & 0.2 & $d$ & 2.0 \\
\hline$S_{1}$ & 0.8 & $t$ & 0.2 \\
\hline$W_{1}$ & 6.45 & $W_{\mathrm{g} 1}$ & 2.5 \\
\hline
\end{tabular}

Tab 1. Geometrical dimensions of the proposed antenna.
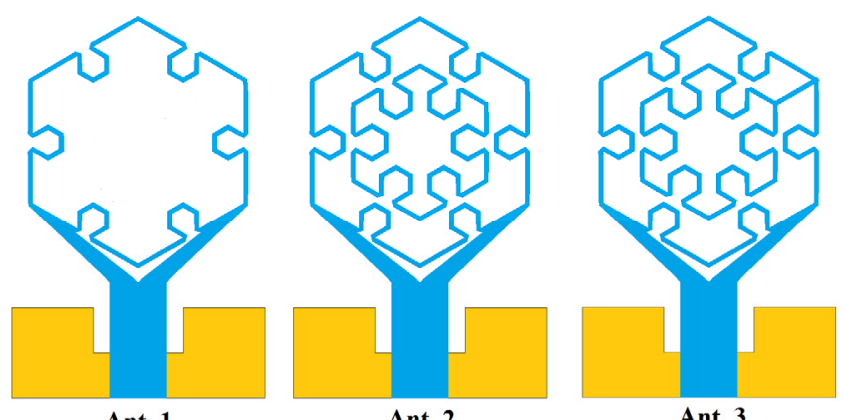

Ant. 1

Ant. 2

Ant. 3

Fig. 2. Geometry of various antennas involved in the design evolution.

The simulated return losses of the proposed antenna when the side length of the small hexagonal open ring $S_{0}$, for the first iteration, of the external fractal ring is changed are presented in Fig. 5. It is clearly seen from the results that by increasing $S_{0}$ from 0.6 to $0.9 \mathrm{~mm}$ with a step of $0.1 \mathrm{~mm}$, the three operating bands are significantly affected. For the first resonance, by increasing the value of $S_{0}$, the resonant frequency shifts to lower frequencies. As for the second band, the lower cut-off frequency is slightly 
shifted to lower frequencies whereas the upper cut-off frequency sifts significantly to higher frequency resulting in bandwidth widening. For the third band, significant shift of the lower cut-off frequency is observed when $S_{0}$ is decreased. Consequently, it can be concluded that optimum results are obtained for $S_{0}=0.8 \mathrm{~mm}$.

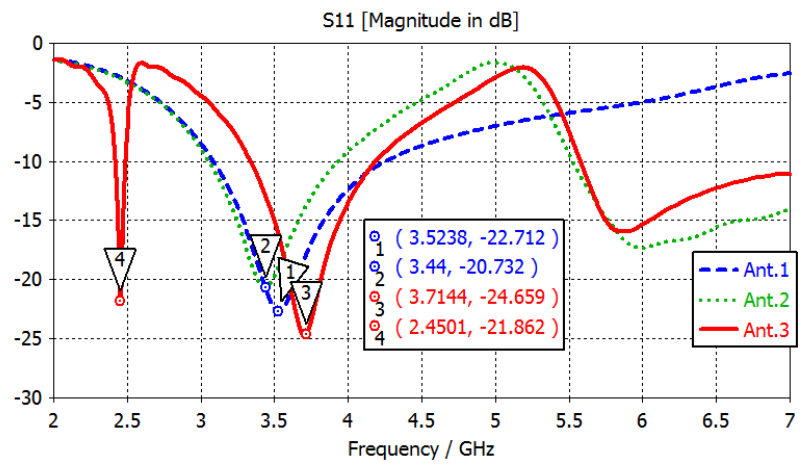

Fig. 3. Reflection coefficient vs frequency of various antenna structures.

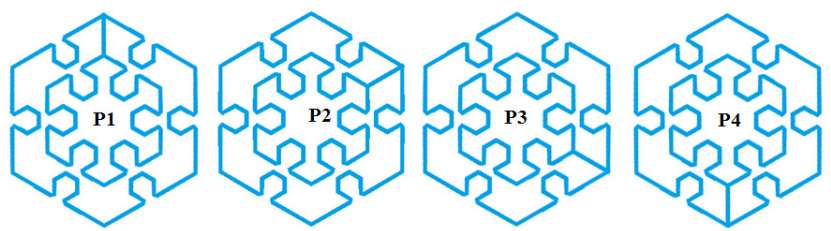

(a)

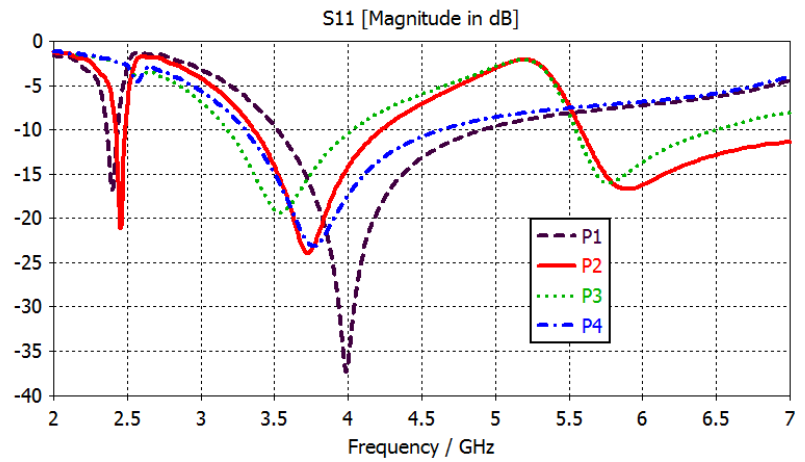

(b)

Fig. 4. (a) Position of the connection strip and (b) effect of the position of the connecting strip on the reflection coefficient.

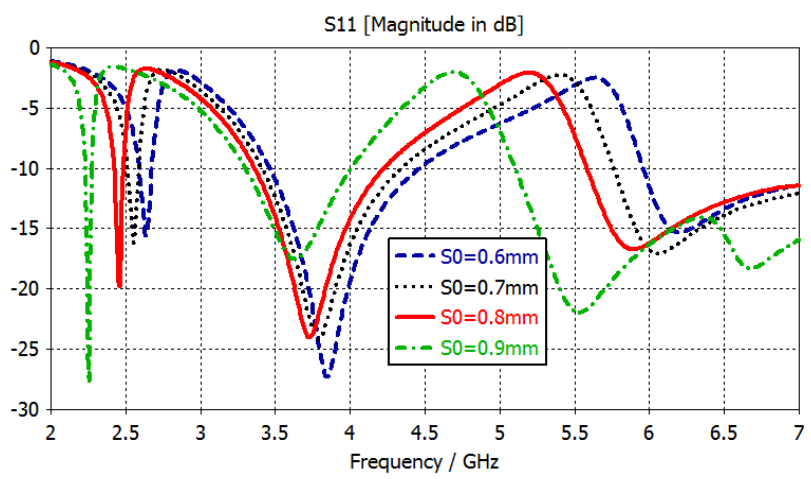

Fig. 5. Effect of $S_{0}$ on the reflection coefficient.

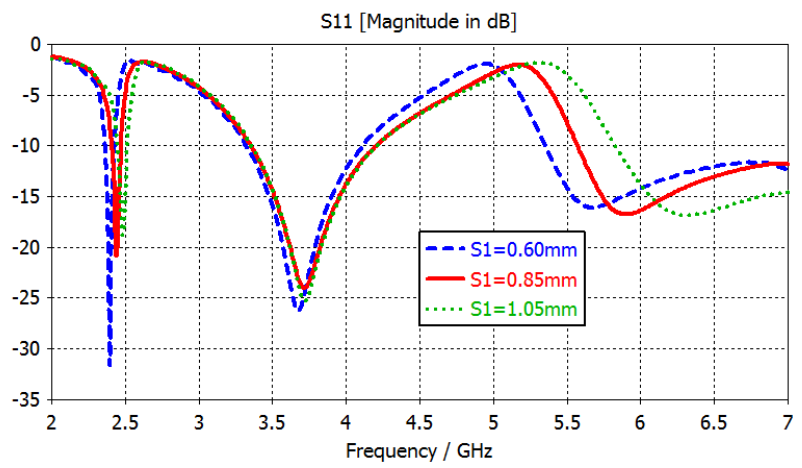

Fig. 6. Effect of variation of $S_{1}$ on the reflection coefficient.

The effect of changing the parameter $S_{1}$ on the antenna return losses characteristics is depicted in Fig. 6. It can be concluded from the figure that by increasing the value of $S_{1}$ the lower cut-off frequency of the third band is shifted toward higher frequency, the first resonance is also slightly increased while the higher cut-off frequency of the second band increases. It can be clearly concluded that optimum results are obtained for $S_{1}=0.85 \mathrm{~mm}$.

To further understand the operating mechanism of the proposed antenna, the current distribution at the three resonant frequencies are simulated and presented in Fig. 7. At the first resonant frequency, the current is mostly concentrated on the two fractal rings. Thus this resonance can be finely tuned by changing the parameters of the radiating rings. Large concentration of current is seen on the outer fractal ring at the second resonance. Accordingly, this resonance can be controlled by changing the outer ring dimensions. At the last operating frequency of $5.8 \mathrm{GHz}$, high concentration of current occurs on the feed line and on the two fractal rings.

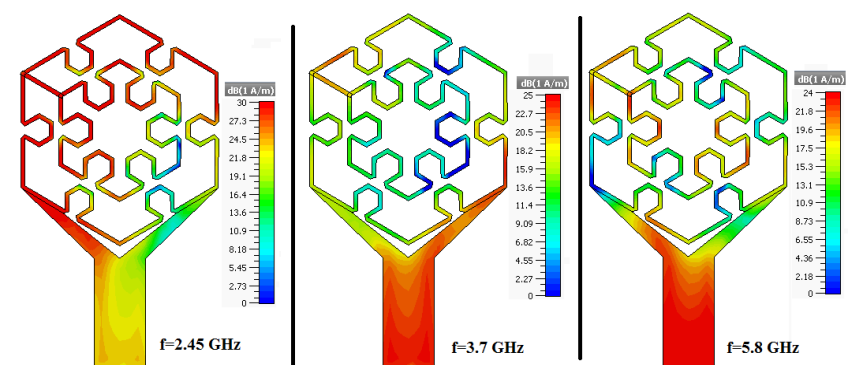

Fig. 7. Simulated current distribution at resonant frequencies.

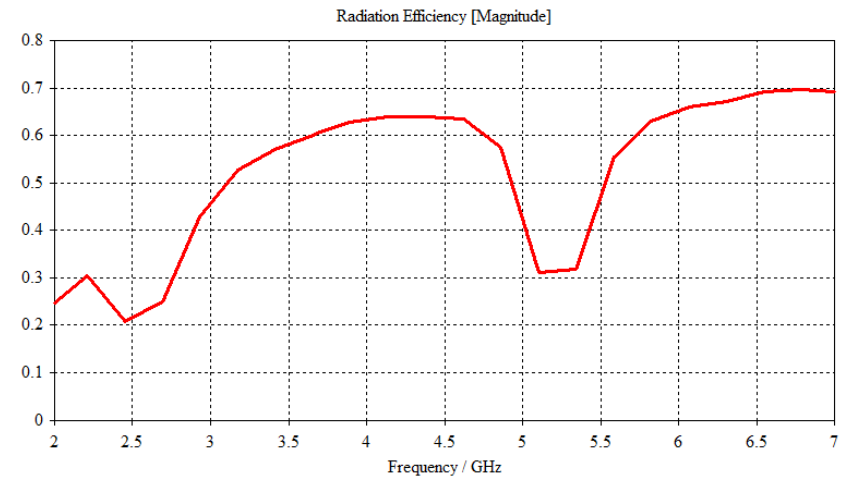

Fig. 8. Simulated radiation efficiency versus frequency. 
This band can be controlled by changing the fractal rings configuration and dimension.

The antenna radiation efficiency is simulated and is plotted in Fig. 8. A peak gain of about $-6.4,-1.5$, and $-2 \mathrm{~dB}$ are observed at $2.45,3.7$, and $5.8 \mathrm{GHz}$, respectively. Also, the maximum radiation efficiency of about $30 \%$, $60 \%$, and $62 \%$ is observed at $2.45,3.7$, and $5.8 \mathrm{GHz}$, respectively.

\section{Simulation and Measurement Results}

Figure 9 shows the proposed antenna fabricated on a low cost widely available FR4 substrate of thickness $1.6 \mathrm{~mm}$, relative permittivity 4.3 , and loss tangent of 0.02 . The simulated and measured return losses results of the antenna are illustrated in Fig. 10. It can be observed that the simulated and measured results are in good agreement, showing a tri-band operation with measured 10-dB impedance bandwidths of $686 \mathrm{MHz}(1814-2500 \mathrm{MHz}, 31.8 \%)$, $1770 \mathrm{MHz} \quad(2967-4737 \mathrm{MHz}, \quad 45.9 \%)$ and $1461 \mathrm{MHz}$ (5539-7000 MHz, $23.3 \%$ ). The slight difference seen between the simulated and the measured results is basically due to the manufacturing tolerances and the uncertainty of the thickness and dielectric relative constant of the substrate added to the quality of the SMA connector which contributes in the discrepancy recorded between the simulated and measured results. Furthermore, due to the small size of the antenna the electrical size of the ground plane became small as compared to the wavelength. In this situation, the SMA connector and a part of the VNA connecting cable act as an additional ground plane [26]. Consequently, the current will flow back from the antenna to the connecting cable. However, the obtained bandwidth covers widely the WLAN $(2.4,5.6$ and $5.8 \mathrm{GHz})$ and WiMAX $(3.5 \mathrm{GHz})$ applications.

The antenna radiation pattern has been measured in an anechoic chamber. The simulated and measured radiation patterns of the proposed antenna in the $\mathrm{E}$ and $\mathrm{H}$ planes at different frequencies $(2.45,3.7 \mathrm{GHz}$, and $5.8 \mathrm{GHz})$ are plotted in Fig. 11. For all frequencies, the antenna has a monopole-like radiation pattern in the E-plane and an omnidiretional radiation pattern in the H-plane which makes it well-suited for the intended applications. The slight difference between measured and simulated radiation patterns are attributed to perturbation in the radiation pattern introduced by the positioner during the measurement process and the inaccuracies introduced by the measurement setup.

A comparison between the proposed antenna and other antennas reported in the literature is presented in Tab. 2. By comparing the reported antennas footprints, it is clearly seen that the proposed antenna has the smallest one. Consequently, it can be concluded that the proposed antenna achieves significant size reduction. Moreover, in terms of impedance matching performance, the proposed antenna outperforms almost all the reported antennas.

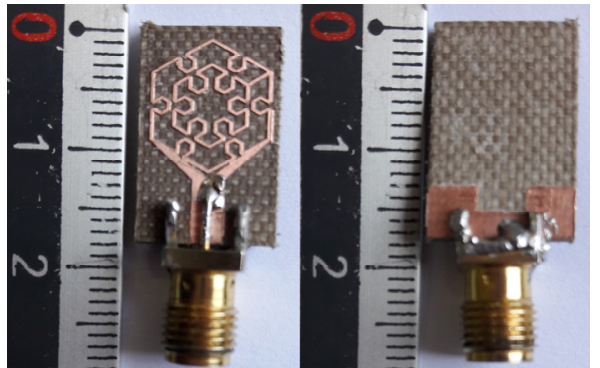

Fig. 9. Fabricated prototype of the proposed antenna.

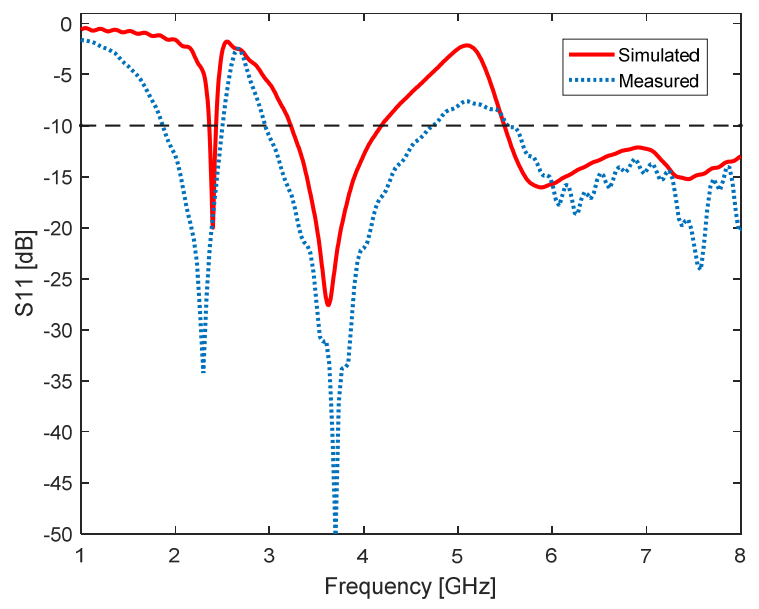

Fig. 10. Simulated and measured reflection coefficient of the proposed antenna.
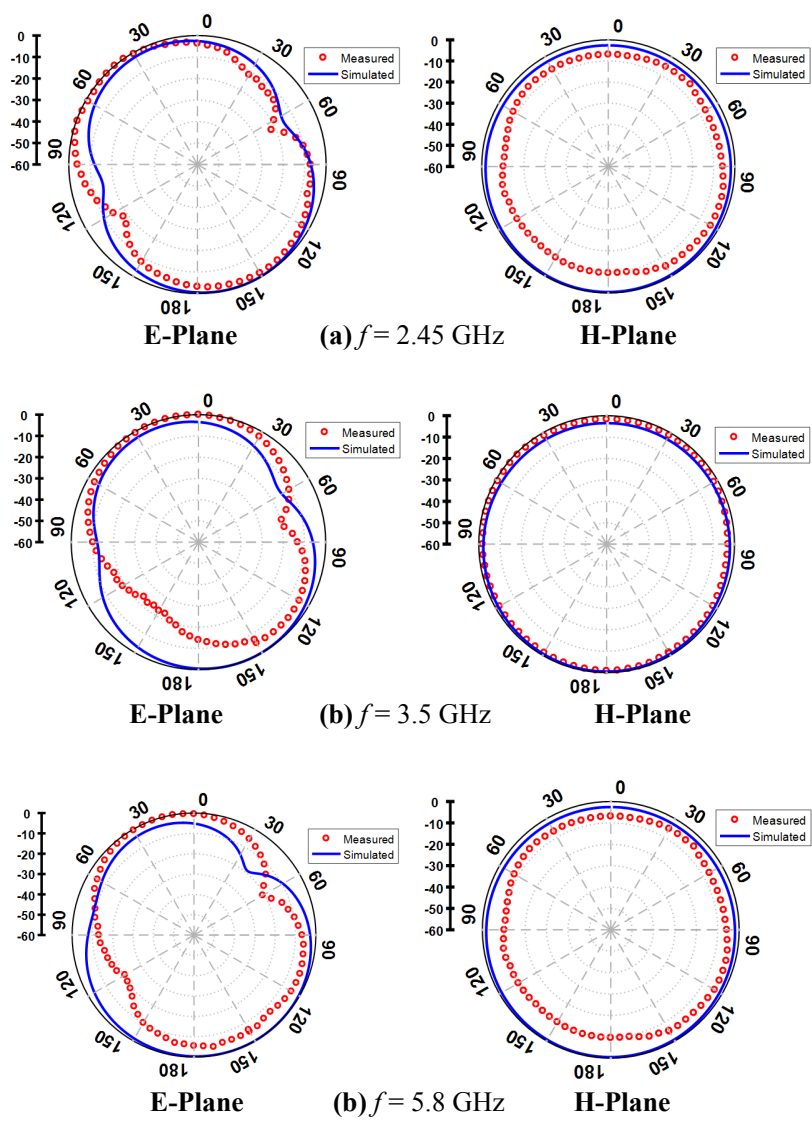

Fig. 11. Simulated and measured radiation pattern of the proposed antenna at different frequencies. 


\begin{tabular}{|c|c|c|c|}
\hline Ref. & $\begin{array}{c}\text { Frequency } \\
(\mathrm{GHz})\end{array}$ & $\begin{array}{c}\text { Antenna } \\
\text { Footprint }\end{array}$ & $\begin{array}{c}\text { Bandwidth } \\
(\%)\end{array}$ \\
\hline [20] & $\begin{array}{c}2.5 \\
3.47 \\
5.75\end{array}$ & $0.022 \lambda_{0}^{2}$ & $\begin{array}{l}6.45 \% \\
3.03 \% \\
5.9 \%\end{array}$ \\
\hline [21] & $\begin{array}{l}1.9 \\
2.5\end{array}$ & $0.062 \lambda_{0}^{2}$ & $\begin{array}{l}5.8 \% \\
4.0 \%\end{array}$ \\
\hline [22] & $\begin{array}{l}2.4 \\
3.5\end{array}$ & $0.026 \lambda_{0}^{2}$ & $\begin{array}{l}5.7 \% \\
6.3 \%\end{array}$ \\
\hline [23] & $\begin{array}{l}2.4 \\
5.2\end{array}$ & $0.102 \lambda_{0}^{2}$ & $\begin{array}{c}10.3 \% \\
19 \% \\
\end{array}$ \\
\hline [24] & $\begin{array}{l}2.4 \\
3.5\end{array}$ & $0.024 \lambda_{0}^{2}$ & $\begin{array}{c}123.5 \% \\
24 \%\end{array}$ \\
\hline [25] & $\begin{array}{l}2.45 \\
3.50 \\
5.35\end{array}$ & $0.113 \lambda_{0}^{2}$ & $\begin{array}{l}2.0 \% \\
2.0 \% \\
5.7 \%\end{array}$ \\
\hline This work & $\begin{array}{l}2.4 \\
3.5 \\
5.8\end{array}$ & $0.016 \lambda_{0}^{2}$ & $\begin{array}{l}31.8 \% \\
45.9 \% \\
23.3 \%\end{array}$ \\
\hline
\end{tabular}

Tab. 2. Comparison between the proposed antenna size and application bands with other compact antennas.

\section{Conclusion}

A novel miniaturized tri-band antenna for wireless communication has been designed, fabricated and tested. The proposed antenna consists of a two concentric fractal radiating rings fed with a $\mathrm{Y}$-shaped microstrip line. By connecting the two fractal rings tri-band operation along with size reduction have been achieved. The proposed antenna has exhibited omnidirectional radiation patterns in the three operating bands. Furthermore, the measured results of the proposed antenna with compact size of $9.3 \times 17 \mathrm{~mm}^{2}$ have shown good agreement with the simulated ones.

\section{References}

[1] FERTAS, K., KIMOUCHE, H., CHALLAL, M., et al. Design and optimization of a CPW-fed tri-band patch antenna using genetic algorithms. ACES Journal - Applied Computational Electromagnetics Society Journal, 2015, vol. 30, p. 754-759.

[2] FERTAS, K., KIMOUChe, H., CHALlal, M., et al. An optimized shaped antenna for multiband applications using Genetic Algorithm. In 2015 4th International Conference on Electrical Engineering (ICEE). Boumerdes (Algeria), 2015, p. 1-4. DOI: 10.1109/INTEE.2015.7416757

[3] DAI, X. W., LI, L., WANG, Z.-Y., et al. High isolation and compact MIMO antenna system with defected shorting wall. International Journal of Microwave and Wireless Technologies, 2015 , vol. 7 , p. $167-172$. DOI: $10.1017 /$ S1759078714000580

[4] TIRADO-MÉNDEZ, J. A., JARDÓN-AGUILAR, H., ITURBIDE-SÁNCHEZ, F., et al. A proposed defected microstrip structure (DMS) behavior for reducing rectangular patch antenna size. Microwave and Optical Technology Letters, 2004, vol. 43, no. 6, p. 481-484. DOI: $10.1002 /$ mop. 20508

[5] ANSAL, K. A., SHANMUGANANTHAM, T. Compact ACS-fed antenna with DGS and DMS for WiMAX/WLAN applications. International Journal of Microwave and Wireless Technologies, 2016, vol. 8, no. 7, p. 1095-1100. DOI: 10.1017/S1759078715000537
[6] DJAFRI, K., CHALLAL, M., AKSAS, R., et al. A compact ACSfed tri-band microstrip monopole antenna for WLAN/WiMAX applications. Presented at the International Conference on Electronics and New Technologies. M'sila, Algeria, 2017.

[7] WANG, H., SI, L.-M., LV, X. A compact dual-band patch antenna using metamaterial structures. In Applied Computational Electromagnetics Society International Symposium (ACES). Suzhou (China), 2017, p. 1-2.

[8] GUPTA, A., JOSHI, H. D., KHANNA, R. An X-shaped fractal antenna with DGS for multiband applications. International Journal of Microwave and Wireless Technologies, 2017, vol. 9, no. 5, p. 1075-1083. DOI: 10.1017/S1759078716000994

[9] SINGHAL, S., GOEL, T., SINGH, A. K. Hexagonal tree shaped ultra-wideband fractal antenna. International Journal of Electronics Letters, 2017, vol. 5, no. 3, p. 335-348. DOI: $10.1080 / 21681724.2016 .1218056$

[10] CHOUKIKER, Y. K., SHARMA, S. K., BEHERA, S. K. Hybrid fractal shape planar monopole antenna covering multiband wireless communications with MIMO implementation for handheld mobile devices. IEEE Transactions on Antennas and Propagation, 2014, vol. 62 , no. 3, p. 1483-1488. DOI: 10.1109/TAP.2013.2295213

[11] SINGHAL, S., GOEL, T., KUMAR SINGH, A. Inner tapered tree-shaped fractal antenna for UWB applications. Microwave and Optical Technology Letters, 2015, vol. 57, no. 3, p. 559-567. DOI: 10.1002/mop. 28900

[12] VARAMINI, G., KESHTKAR, A., NASER-MOGHADASI, M. Compact and miniaturized microstrip antenna based on fractal and metamaterial loads with reconfigurable qualification. $A E U$ International Journal of Electronics and Communications, 2018, vol. 83, p. 213-221. DOI: 10.1016/j.aeue.2017.08.057

[13] ANGUERA, J., DANIEL, J. P., BORJA, C., et al. Metallized foams for antenna design: Application to fractal-shaped Sierpinskicarpet monopole. Progress In Electromagnetics Research. PIER 2010, vol. 104, p. 239-251. DOI: 10.2528/PIER10032003

[14] IQBAL, M. N., UR-RAHMAN, H., JILANI, S. F. An ultrawideband monopole fractal antenna with coplanar waveguide feed. International Journal of Antennas and Propagation, 2014, p. 1-7. DOI: $10.1155 / 2014 / 510913$

[15] RADONIĆ, V., PALMER, K., STOJANOVIĆ, G., et al. Flexible Sierpinski carpet fractal antenna on a Hilbert slot patterned ground. International Journal of Antennas and Propagation, 2012, p. 1-7. DOI: $10.1155 / 2012 / 980916$

[16] NAJI, D. K. Compact design of dual-band fractal ring antenna for WiMAX and WLAN applications. International Journal of Electromagnetics and Applications, 2016, vol. 6, no. 2, p. 42-50. DOI: $10.5923 /$ j.jijea.20160602.03

[17] PUENTE, C., ROZAN, E., ANGUERA, J. Space-filling Miniature Antennas. US Pat. 7,202,822.

[18] RISCO, S., ANGUERA, J., ANDÚJAR, A., et al. Coupled monopole antenna design for multiband handset devices. Microwave and Optical Technology Letters, 2010, vol. 52, no. 2, p. 359-364. DOI: $10.1002 / \mathrm{mop} .24893$

[19] JUNG, J. H., CHOO, H. PARK, I. Design and performance of small electromagnetically coupled monopole antenna for broadband operation. IET Microwave, Antennas and Propagation, 2007, vol. 1, no. 2, p. 536-541. DOI: 10.1049/iet-map:20050065

[20] ALI, T., BIRADAR, R. C. A triple-band highly miniaturized antenna for WiMAX/WLAN applications. Microwave and Optical Technology Letters, 2018, vol. 60, p. 466-471. DOI: 10.1002/mop.30993

[21] YUE, T., JIANG, Z. H., PANARETOS, A. H., et al. A compact dual-band antenna enabled by a complementary split-ring resonator-loaded metasurface. IEEE Transactions on Antennas and 
Propagation, 2017, vol. 65, no. 12, p. 6878-6888. DOI: 10.1109/TAP.2017.2758821

[22] MALIK, J., PATNAIK, A., KARTIKEYAN, M. A compact dualband antenna with omnidirectional radiation pattern. IEEE Antennas and Wireless Propagation Letters, 2015, vol. 14, p. 503-506. DOI: 10.1109/LAWP.2014.2370651

[23] LU, J.-H., HUANG, H.-S. Planar compact dual-band monopole antenna with circular polarization for WLAN applications. International Journal of Microwave and Wireless Technologies, 2016, vol. 8, no. 1, p. 81-87. DOI: 10.1017/S1759078714001329

[24] NAIDU, P. V. Printed V-shape ACS-fed compact dual band antenna for Bluetooth, LTE and WLAN/WiMAX applications. Microsystem Technologies, 2017, vol. 23, no. 4, p. 1005-1015. DOI: 10.1007/s00542-016-2939-7

[25] BEKASIEWICZ, A., KOZIEL, S. Miniaturized uniplanar triple-band slot dipole antenna with folded radiator. Microwave and Optical Technology Letters, 2018, vol. 60, no. 2, p. 386-389. DOI: $10.1002 / \mathrm{mop} .30971$

[26] LIU, L., WENG, Y., CHEUNG, S., et al. Modeling of cable for measurements of small monopole antennas. In Loughborough Antennas and Propagation Conference (LAPC). Loughborough (UK), 2011, p. 1-4. DOI: 10.1109/LAPC.2011.6114153

\section{About the Authors ...}

Kahina DJAFRI was born on January $21^{\text {st }}, 1982$, in Bejaia, Algeria. She received the Engineer degree in June 2005 from the National Polytechnic School of Algiers, Algeria; the M.S. degree in March 2008 from the National Polytechnic School. Currently, she is a Ph.D. student in the Institute of Electrical and Electronic Engineering of Boumerdes University. Her research interests include microwave propagation and antennas, antenna miniaturization techniques.

Mouloud CHALLAL was born on March 6, 1976, in Algiers, Algeria. He received the Electronics and Communication Engineering degree from University of BabEzzouar, Algiers, Algeria, in April 1999, the M.Sc. degree in Microwave and Communication from Ecole Nationale Polytechnique, Algiers, Algeria, in Dec. 2001 and the doctorate degree from University of Boumerdes, Algiers, Algeria, in Mar. 2012. Currently, he is a lecturer in the
Institute of Electrical and Electronic Engineering of Boumerdes University. His research interests include $\mathrm{RF} /$ microwave circuits, design and analysis of microstrip filters, DGSs behaviors, wireless communication systems, microstrip antenna array analysis, synthesis and design. Dr. Challal is a member of IEEE and European Microwave Association (EuMA), and is a reviewer of several international journals and conferences. He is also, the treasurer of IEEE Algeria Subsection.

Rabia AKSAS was born in 1950, Algeria. He received the M.S. and Doctorate degrees in Electronics from the National Polytechnic School (presently ENSP) of El-Harrach, Algiers, Algeria, respectively in 1982 and 1995. Currently, he is a Senior Professor in the Electronics Department, National Polytechnic School of Algiers. Throughout his long career, he has been teaching various courses such as Telecommunication Systems, Vibrations and Waves, Electromagnetic Field, Radio Wave Propagation and Antennas. In addition to his teaching load, he worked in various projects in the antennas field as a research director. His research interests are in the areas of electromagnetic field theory, microwaves, propagation and antennas. Aksas has published over 44 scientific papers in international refereed journals and conferences.

Faiza MOUHOUCHE was born in Boumerdes, Algeria. She received the Engineer and Magister degrees in 2005 and 2010 from the National Institute of Electricity and Electronics of Boumerdes, Algeria, respectively. She is currently pursuing her Ph.D. degree from the same institute. She is a member team in the research of communication systems. Her research interests include RF/microwaves, antennas and propagation.

Mokrane DEHMAS was born in April 1967 in Tizi-Ouzou, Algeria. He received the Engineer and Magister degrees in the National Institute of Electricity and Electronics (INELEC-Boumerdes, Algeria) respectively in 1991 and 1996. He is currently an associate professor in the Institute of Electrical and Electronic Engineering of the University of Boumerdes and a member of the research team in communication systems. His main fields of interest are semiconductor devices modeling and microstrip radiating structures. 